\title{
As matrizes filosóficas e sociológicas das teorias da comunicação ${ }^{1}$
}

Leandro Marshall ${ }^{2}$

\section{Resumo}

Este trabalho busca fazer a genealogia das Teorias da Comunicação de Massa desenvolvidas no Século XX. A pretensão é buscar e identificar as origens filosóficas e sociológicas das principais teorias, relacionando, portanto, a trajetória genética epistemológica das ideias que marcaram o pensamento comunicacional e determinaram a formatação, sobretudo, das teorias crítica e funcionalista. $\mathrm{O}$ trabalho, desenvolvido por meio de pesquisa teórica e bibliográfica, busca estabelecer um quadro histórico coerente sobre a epistemologia das Teorias da Comunicação, apresentadas em muitas das obras contemporâneas sem a devida contextualização paradigmática original. Palavras-chave: Teorias da comunicação. Teorias do conhecimento. Epistemologia da comunicação.

\section{Introdução}

O ser humano é, por natureza, um ser que interroga a realidade e busca extrair dela a verdade dos fenômenos humanos, naturais ou sociais. A verdadeira filosofia nasceu exatamente a partir desse pressuposto.: descobrir as estruturas elementares que constituem a essência das coisas e dos acontecimentos do mundo. De um modo ou de outro, a interrogação dos filósofos e, mais tarde, dos sociólogos, foi sempre a de tentar entender quais são as motivações, as causas ou os fatores que determinam a natureza humana e a ordem fundadora dos fenômenos mundanos.

\footnotetext{
${ }^{1}$ Trabalho apresentado na NP Teoria da Comunicação, evento componente do XXXI Congresso Brasileiro de Ciências da Comunicação.

${ }^{2}$ Doutor em Comunicação/Tecnologias do Imaginário pela PUC/RS. Mestre em Teorias da Comunicação pela UMESP/SP. Especialista em Epistemologia da Comunicação Social pela UPF/RS. Professor de Filosofia e Antropologia no UNICEUB-DF Analista em Ciência e Tecnologia do IBICT/MCT.
} 
Como passo inicial, a filosofia estabeleceu que a busca do conhecimento pelo pensamento humano deveria obedecer a uma organização primária. Essa organização tem quatro elementos: um sujeito (o homem) que percorre um método (o caminho) para decifrar a verdade (veritas) do objeto (a realidade, isto é, os fenômenos ou fatos do mundo natural, humano ou social). Não há filosofia ou sociologia do conhecimento que não obedeça a essa ordem fundamental.

Essa ordem é base do que chamamos de Teoria do Conhecimento, a matriz de todas as operações físicas, metafísicas ou pós-metafísicas, que determina o caminho inexorável percorrido pelo homem em busca da verdade última para livrálo das profundezas do obscurantismo e do medo. Para encontrar o conhecimento puro sobre a realidade, o homem decidiu aventurar-se em uma verdadeira batalha das almas. Negou seus mitos e suas lendas que lhe davam um colchão confortável de certezas, para adentrar o inferno de Dante e afugentar o vazio da sua insignificância.

A Teoria do Conhecimento representa, ipso fato, o campo maior de todas as teorias. Ela não só procura desvendar as senhas da realidade, mas dita qual o caminho correto a ser percorrido para que o sujeito conheça a verdadeira essência do objeto.

É bem verdade que, como tratamos aqui de uma empreitada humana, não teremos um único caminho, tampouco uma única versão para a realidade (o objeto). O dissenso das ideias no pensamento humano é uma característica peculiar de nossa espécie, obstinada permanentemente em construir, desconstruir e reconstruir novas perspectivas heurísticas para o que acaba tendo apenas precariamente e durante algum tempo o foro de verdade. Como demonstraram Thomas Kuhn, em A Estrutura das Revoluções Científicas, e Michel Foucault, no conjunto de sua obra, cada época teve suas certezas e crenças inexoráveis, a despeito das evidências em contrário e das transformações 'normais' no permanente processo de construção do conhecimento.

Não há, pois, um único caminho para a verdade. Acreditamos sim que existem pelo menos sete caminhos. Johannes Hessen foi quem melhor descreveu estes sete principais caminhos trilhados pelo processo do conhecimento, ao longo da história. São eles: o dogmatismo, o ceticismo, o objetivismo, o subjetivismo, o relativismo, o pragmatismo e o criticismo. 
O dogmatismo deriva, como diz o próprio sentido da palavra dogma (originária do grego), do conjunto de doutrinas estabelecidas por um regime de crenças que se consideram acima do processo de conhecimento. Nessa vertente, a verdade é dada, é concedida e é verdadeira por ser obviamente verdadeira.

A possibilidade e a realidade do contato entre sujeito e objeto são pura e simplesmente pressupostas. É auto-evidente que o sujeito apreende seu objeto, que a consciência apreende aquilo que está diante dela. Esse ponto de vista é sustentado por uma confiança na razão humana que ainda não foi acometida por nenhuma dúvida (HESSEN, 2000, p. 29).

Incluem-se no rol das verdades dogmáticas todas as esferas da percepção, dos valores e do pensamento. Estão envolvidos aí todas as mitologias, as lendas, as escatologias, os estereótipos, os clichês, os adágios e toda sorte de crenças incrustadas no senso comum ordinário. Nesses domínios, as certezas são onipotentes e, por isso, sequer precisam ser questionadas.

A expressão maior dessa vertente de conhecimento é o dogmatismo religioso. Seja qual for o tipo de crença ou o tipo de estrutura teológica por trás desse castelo de certezas, a religião é imperativa e está acima do bem e do mal da razão. Ela não é passível de dúvidas, visto que ela é a própria negação da existência da dúvida.

Por sua própria natureza, o dogmatismo é a mais antiga forma de 'conhecimento' humano. Ela foi a explicação maior dos povos primitivos para os acontecimentos naturais ou sobrenaturais e chegou a pautar o pensamento de alguns dos sofistas. Em certo sentido, o aspecto primordial do crer e não do saber, contido na essência dessa teoria, faz com que o dogmatismo seja mais apropriado para uma teoria da crença do que para uma teoria do conhecimento.

O surgimento da corrente do ceticismo (do grego sképtesthai, considerar, examinar) é, de certo modo, uma reação ao mundo inabalável e inquestionável do dogmatismo. Os seguidores desse modo de pensamento têm uma desconfiança, uma descrença radical na possibilidade do conhecimento autoevidente. Para eles, tudo deve ser questionado, inclusive a própria possibilidade de conhecermos o mundo tal qual ele se apresenta.

Os céticos duvidam da existência da verdade como premissa básica do conhecimento. Para eles, toda certeza é uma impossibilidade ontológica, haja vista 
que o objeto é matéria traiçoeira e escorregadia. O objeto não pode ser apreendido, uma vez que está assentado em uma instância do conhecimento além dos poderes cognitivos do sujeito.

Enquanto o dogmático encara a possibilidade de contato entre sujeito e objeto como auto-evidente, o cético a contesta. Para o ceticismo, o sujeito não seria capaz de apreender o objeto. O conhecimento como apreensão efetiva do objeto seria, segundo ele, impossível (HESSEN, 2000, p. 31).

Hessen (2000, p. 32) argumenta ainda apropriadamente que "enquanto o dogmatismo, de certo modo, desconsidera o sujeito, o ceticismo não enxerga o objeto. Seu olhar está colado de modo tão unilateral ao sujeito, à função cognoscente, que desconhece por completo a referência ao objeto".

Os representantes mais antigos dessa teoria do conhecimento são: Pirro de Elis (360-270 a.C), Arcesilau (241 a.C) e Carnéades (129 a.C). Todos consideraram em suas vidas que uma proposição jamais poderia ser absolutamente verdadeira. No máximo, poderíamos argumentar que a proposição poderia ser verdadeira ou verossímil. Na era moderna, encontramos seguidores dessa vertente em Montaigne (1592), Hume e Bayle.

O caráter radical do ceticismo foi a inspiração para uma das mais intensas teorias do conhecimento de nossa era moderna: o objetivismo. Centrado na concepção de que o centro de gravidade do saber é o objeto, os defensores desse pensamento advogam que todo conhecimento só pode partir do objeto, isto é, o objeto é que determina o sujeito. No objetivismo, o objeto é algo autoevidente, pronto, uma realidade concreta que se apresenta como uma evidência inquestionável do mundo. Para essa vertente, "os objetos são algo dado, apresentando uma estrutura totalmente definida que será, por assim dizer, reconstruída pela consciência cognoscente" (HESSEN, 2000, p. 70).

Neste mundo de pura concretude, o que resta então para o sujeito? Segundo os objetivistas, o ser é apenas uma coisa, um fato, uma extensão objetal do mundo. O papel do sujeito é apreender a realidade tal como ela se apresenta, sendo ele mesmo parte concreta dessa realidade. Na visão de Hessen, Platão foi o primeiro pensador a formular o problema do objetivismo através da sua teoria do idealismo. Sua filosofia seria a própria 'formulação clássica' do objetivismo, na medida em que “as idéias são realidades objetivamente dadas" (HESSEN, 2000, p. 70). 
A principal corrente do objetivismo acabou se concretizando na escola de pensamento do positivismo. Contaminado pelo princípio da dúvida metódica (não radical) de Descartes, os positivistas acreditavam que o erro do conhecimento reside no pensamento metafísico, mas pode ser apreendido na própria física (do grego, physis, natureza). Nesse sentido, o positivismo mantém o ceticismo relacionado à subjetividade, mas passa a aceitar a possibilidade na verdade da objetividade dos fatos sociais.

A partir de Auguste Comte (1798-1857), Herbert Spencer (1820-1903) e Francis Bacon, os positivistas acreditam que "devemos nos ater ao que é positivamente dado, aos fatos imediatos da experiência, mantendo-nos em guarda contra toda e qualquer especulação metafísica. Não existe saber ou conhecimento filosófico-metafísico, mas somente o saber e o conhecimento das ciências particulares" (HESSEN, 2000, p. 35).

Nessa vertente, dominante durante toda a era moderna, os céticos seguiram à risca os postulados de Comte, enunciados basicamente pela Lei dos três estados: o teológico, o metafísico e o positivista (ou científico). Representativos do pensamento humano durante sua trajetória civilizacional (segundo a concepção deste teórico), os três estados sustentam o paradigma de que somente através da apreensão da verdade por meio do exame acurado do objeto é que podemos ter a verdade absoluta para tudo.

O estado teológico (teo significa deus, em grego) representa o mundo primitivo com seus tabus, mitos, lendas e religiosidades. Nessa época, não havia nenhum tipo de procedimento para a descoberta das causas finais dos acontecimentos mundanos e, por isso, os saberes emanavam como dogmas vindos do além. Os homens buscavam na fé e na crença a origem das suas graças e desgraças. Se a tempestade destruía a plantação, isso era obra da ira dos deuses. Se um líder da comunidade morria, isso representava o início de uma era de infortúnio. Se os animais desapareciam subitamente de uma determinada região, isso era sinal de que algo novo e misterioso estava para acontecer.

O estado metafísico (meta, sobre, e física, natureza) denotava diretamente o modelo de pensamento fundado pela filosofia. Para os positivistas, o pensamento filosófico era apenas estéril, meramente especulativo, andava em círculos sem 
nunca encontrar o modelo de vida ideal para os homens. Cada filósofo e cada nova estrutura de pensamento era apenas fonte de novas dúvidas, nunca de certezas e verdades absolutas. O principal erro era, sobretudo, buscar as explicações para os fenômenos do mundo numa esfera acima dele, a metafísica, negando as evidências dos fatos sociais e sua concretude.

Já o estado positivo ou científico era a redenção final da civilização humana. Baseado num método de investigação empírica e experimental, o positivismo poderia dar finalmente as respostas que os homens tanto procuravam para os fenômenos mundanos. Descartando-se qualquer explicação teológica ou metafísica, os positivistas enxergaram no objeto a raiz do verdadeiro conhecimento humano. Submetido a testes, experimentações e técnicas indutivas, o objeto revelaria, enfim, as respostas para todos os acontecimentos.

Diante da força do pensamento positivista, sobretudo a partir do século XIX, os pensadores filiados à teoria do conhecimento subjetivista foram obrigados a mergulhar no ostracismo e na descrença da comunidade científica. Ao contrário dos positivistas, o subjetivismo acredita que a verdade reside primordialmente no sujeito, origem e causa de todos os fenômenos humanos, mentais ou sociais. Para eles, o objeto é uma invenção do imaginário humano e, portanto, consequência e não causa da realidade.

O ponto de partida para a busca da verdade, nessa concepção, reside no processo original da própria construção da realidade. É a mente ou o sujeito que constrói o objeto e, portanto, não podemos inverter o processo de descoberta do conhecimento. Se quisermos apreender e entender o objeto, devemos partir do sujeito para compreender tanto o sujeito quanto o objeto. "O subjetivismo, como seu nome já indica, restringe a validade da verdade ao sujeito que conhece e que julga" (HESSEN, 2000, p. 36).

É importante ressaltar que o pensamento subjetivista é bastante antigo na tradição filosófica ocidental. Ele aparece em Plotino e Santo Agostinho, mas ganha solidez e carga epistemológica com o kantismo e com a Escola de Marburgo.

Na visão modernista, o problema do sujeito e do objeto é desconstruído e, de certa forma, invertido. Não é o objeto que determina o sujeito, mas o contrário. O sujeito (a subjetividade humana) é quem produz o objeto (a realidade), criado 
na esfera anterior da consciência. Nessa visão, o mundo inteiro é uma invenção da mente humana, que arbitrou e nominou as coisas, os fatos, os sentimentos, as abstrações e os acontecimentos concretos e imaginários. "Não há objetos independentes da consciência, mas, ao contrário, todos os objetos são produções da consciência, produtos do pensamento (HESSEN, 2000, p. 73).

De certo modo, o subjetivismo é uma vertente de pensamento com parentesco bastante próximo de outra teoria do conhecimento: o relativismo. Ambas acreditam que a verdade só pode emanar do sujeito e nunca do objeto. A diferença está em que o subjetivismo acredita que todos os homens podem chegar a uma verdade válida universalmente, e o relativismo crê que, se existe a verdade, ela é apenas individual, restrita a cada ser humano.

O relativismo, como o próprio nome diz, considera que não há nada absoluto, mas que tudo é relativo ao indivíduo, às suas idiossincrasias e a fatores externos, como a época, a situação e a uma dada marca cultural. Em certo sentido, os relativistas são uma espécie de céticos radicais que negam a possibilidade do conhecimento, de o sujeito apreender o objeto, a não ser nas situações específicas e singulares vividas por cada um dos sujeitos.

O representante maior dos relativistas foi o filósofo Protágoras e sua célebre proposição de que "o homem é a medida de todas as coisas" (pánton khremáton métron ánthropos). Protágoras, que ficou mais conhecido como um sofista, influenciou uma grande geração de pensadores, pois, em certa medida, o relativismo seduz e atrai todos aqueles indivíduos mais arraigados às suas crenças pessoais, que recusam a se aventurar pelos labirintos herméticos do conhecimento.

Nossa sexta teoria do conhecimento, o pragmatismo, tem a ver, lato sensu, com a relação entre sujeito e o desejo de conhecimento. Enquanto os dogmáticos, os céticos, os objetivistas, os subjetivistas e os relativistas especulam sobre a possibilidade de o sujeito apreender o conhecimento, os pragmatistas acreditam que o ser humano, em sua realidade mundana e concreta, não é um ser vocacionado para a aventura da verdade, e sim para a aventura da vida. Em outras palavras, os pragmatistas dizem que o homem não nasceu e vive direcionado para a busca das verdades da vida, mas sim para experimentar e gozar os prazeres dos eventos mundanos. 
Ao invés de desejar a verdade, o homem pragmático busca o útil e o benéfico para a satisfação das suas vontades e de seus interesses. Nesse sentido, o sujeito não é um ser cuja preocupação imediata seja pensar a realidade, mas o intelecto está voltado para o querer e o agir. Em síntese, é um ser prático, e não teórico.

$\mathrm{O}$ intelecto não foi dado ao homem para investigar e conhecer, mas para que possa orientar-se na realidade. É, dessa determinação prática de fins que o conhecimento humano retira seu sentido e seu valor (HESSEN, 2000, p. 40).

Os principais expoentes do pragmatismo foram William James, criador da expressão, Herbert Schiller e Hans Vaihinger. Hessen inclui nesse rol ainda o próprio Friedrich Nietzsche, filósofo que, em seu ponto de vista, também teria preconizado a renúncia do homem a toda busca pela verdade, enquanto desconstruía ou destruía todo o castelo de verdades erigido pelo Iluminismo.

A última, ou mais recente, teoria do conhecimento é o criticismo. Embora esteja enquadrada como outra vertente das teorias, o criticismo pode ser considerado como uma força de negação dos princípios ontológicos e metafísicos que sustentam as demais vertentes do conhecimento. Criada pelo filósofo alemão Imannuel Kant, o criticismo (do grego Krínein, examinar, pôr à prova) questiona os pressupostos básicos de todas as teorias, colocando em dúvida a própria possibilidade do conhecimento, na forma em que ele foi apresentado até então.

Mesmo considerando que pode haver uma verdade universal e o encontro heurístico entre sujeito e objeto, Kant edifica um método de filosofar do pensamento "que investiga tanto a fonte de suas afirmações e objeções quanto os fundamentos sobre os quais repousam" (HESSEN, 2000, p. 43).

Enquanto as outras teorias falam sobre sujeito, objeto, verdade, método, realidade; o criticismo de Kant indaga: o que é sujeito? O que é objeto? O que é verdade? O que é método? O que é realidade?

E, vai ainda mais longe: Quem disse que o sujeito pensa? O que é pensamento? Quem disse que o pensamento sobre sujeito e objeto está correto? Quem disse que há possibilidade de o sujeito encontrar a verdade por meio do pensamento?

Assim, Kant põe em dúvida todos os pressupostos do pensamento metafísico, sobretudo o cartesiano com seu preceito do 'cogito, ergo sum' (penso, 
logo existo). Para ele, antes de edificarmos construções teóricas sobre o mundo físico e metafísico, temos que colocar em xeque, colocar em prova todas as certezas internas sobre o próprio pensamento e seu mundo de conceitos e nominalismos.

Em outras palavras, o criticismo rejeita qualquer juízo, sentença ou proposição lógica sobre o conhecimento sem que haja um princípio de desconfiança nos limites da razão e um concomitante exercício de crítica prévia contra a própria razão. Por sua dimensão teórica, Hessen chegou a dizer que, comparando todas as teorias do conhecimento, o criticismo é o momento mais avançado e mais maduro de toda a filosofia.

O primeiro passo nos assuntos da razão pura, característico de sua própria infância, é dogmático. O segundo passo é cético e testemunha a cautela de um juízo escolado pela experiência. Agora, porém, é necessário um terceiro passo, o de um juízo adulto e viril (HESSEN, 2000, p. 44).

\section{As teorias da comunicação humana}

As teorias do conhecimento alicerçam o edifício teórico que acabou se consolidando nas matrizes filosóficas, sociológicas e culturais/comunicacionais de nosso tempo. As sete vertentes do saber são um roteiro epistemológico para entendermos a origem e as filiações teóricas das construções contemporâneas sobre a relação entre sujeito e objeto, numa perspectiva mais aproximada dos fatos da cultura e da civilização humana.

Por sua própria natureza, o dogmatismo, o ceticismo (puro) e o relativismo não chegaram a gerar nenhuma matriz teórica importante. O pragmatismo e o criticismo também estão à margem da interpretação dos fenômenos da cultura, fazendo com que nossos pensadores estejam em dívida com o fechamento do círculo de nossas teorias.

Do objetivismo e do subjetivismo, vimos nascerem, sobretudo, a partir do século XIX, três grandes construções filosóficas. O objetivismo serviu de inspiração para o positivismo; o subjetivismo derivou para a fenomenologia; e da antítese das teorias nasceu uma terceira corrente: o materialismo histórico, crítico e dialético. 
O positivismo, como já falamos no item anterior, surgiu com Comte, mas se consolidou com Emile Durkheim. A fenomenologia foi solidificada por Edmund Hurssel, seguido por George Simmel, Gilbert Durand e outros. Já o materialismo histórico e dialético é obra direta do filósofo alemão Karl Marx, acompanhado por Engels, Kosik, Gramsci, Adorno, Althusser e tantos outros.

Figura 1: Relação entre Teorias do Conhecimento e principais TeoriasFilosóficas

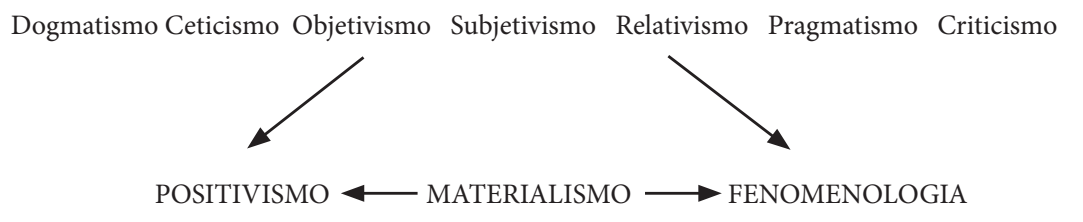

O positivismo comteano e sua receita de objetividade pura pretenderam se tornar a panaceia universal para todos aqueles que estavam determinados a encontrar a revelação do conhecimento. Os positivistas acreditam que a ciência pode encontrar todas as explicações para os fenômenos naturais, humanos ou sociais. Não há outro caminho ou outra possibilidade. A ciência é a salvação e a explicação final em que todos os fatos, do mundo ou da mente são tratados como coisas, e não existe mais lugar para explicações transcendentais místicas , como, por exemplo, Deus.

Entretanto, enquanto August Comte apresentou os postulados de um conhecimento fundado na primazia da objetividade, o francês Emile Durkheim tratou de consolidar o campo da sociologia científica, assentado no primado da ciência empírica. Embalado por uma época de transformações, em que o mundo do feudalismo dava lugar à Revolução Burguesa e à Revolução Industrial, Durkheim acreditava que a nova época deveria estar alicerçada por um sistema teórico fundamentalmente adequado à nova ordem moderna do industrialismo e à sua concepção de progresso.

Durkheim lança as bases desta concepção na obra As Regras do Método Sociológico, na qual ele assegura que todo o universo de fenômenos sociais deve ser tratado como fatos sociais, a exercerem uma força de coerção sobre os seres humanos, que, por sua vez, também são tratados como objetos a serem estudados cientificamente. 
Os homens são tratados como coisas, partículas integrantes do grande objeto científico que é a sociedade. Para Durkheim, o fato social é um elemento dotado de vida própria, externo aos seres, que exerce pressão, condiciona e determina suas ações.

O método sociológico, tal como o praticamos, repousa inteiramente sobre o princípio fundamental de que os fatos sociais devem ser estudados como coisas, isto é, como realidades exteriores ao indivíduo (DURKHEIM, 1930, p. 9-10).

Ao contrário da visão comteana/durkheiniana, objetivista e empírica da ciência, a fenomenologia estuda o objeto (a realidade) e o sujeito a partir da subjetividade humana. Embora a abordagem tenha aparecido no pensamento de Kant, de Hegel (com a Fenomenologia do Espírito) e de Mearlou-Ponty, foi o filósofo Edmund Husserl quem consolidou a disciplina como um novo campo de conhecimento filosófico e sociológico na era moderna.

A fenomenologia de Husserl como o próprio nome indica, acredita que o papel da ciência é tratar os eventos humanos como 'fenômenos', e não como fatos. Husserl defende a ideia de que a função da ciência é encontrar a verdade em sua essência pura e, por isso, prega um retorno ao estudo das 'coisas mesmas'.

Entre o discurso especulativo da metafísica e o raciocínio das ciências positivas deve, pois, existir uma terceira via, aquela que antes de todo raciocínio, nos colocaria no mesmo plano da realidade ou, como diz Husserl, das coisas mesmas (DARTIGUES, 1973, p. 13).

Husserl confiava na possibilidade de enxergarmos a realidade tal qual ela se apresenta, visualizando a coisa em si, debaixo de sua cortina de impressões e ilusões (o que pensadores como Hegel queriam acreditar ser impossível), como:

Falar de uma visão das essências não significará, pois, devotar-se a uma contemplação mística que permitiria a alguns iniciados ver o que o comum dos mortais não vê, mas, ao contrário, ressaltar que o sentido de um fenômeno lhe é imanente e pode ser percebido, de alguma maneira, por transparência (DARTIGUES, 1973, p. 15).

O método de Husserl para o encontro da verdade entre sujeito e objeto é o da análise intencional, ou da redução fenomenológica, em que a consciência é responsável por conceber a realidade, e somente ela, e nela, é que poderá se desvendar 
a essência da realidade. Por isso, diz Husserl que somente a atitude fenomenológica pode compreender que o mundo como sujeito e objeto, exterior e interior, são fenômenos da consciência e não fatos do mundo independentes do sujeito. Ou, nas palavras de Husserl: 'o mundo, na atitude fenomenológica, não é uma existência, mas um simples fenômeno'.

A consciência não é mais, consequentemente, uma parte do mundo, mas o lugar de seu desdobramento no campo original da intencionalidade. Isto significa que o mundo não é em primeiro lugar e em si mesmo o que explicam as filosofias especulativas ou as ciências da natureza, já que essas explicações são posteriores à abertura do campo primordial, mas sim que ele é em primeiro lugar o que aparece à consciência e a ela se dá na evidência irrecusável de sua vivência. O mundo não é assim nada mais que o ele é para a consciência (DARTIGUES, 1973, p. 21).

O materialismo histórico, crítico e dialético, também denominado de Ciência Social Crítica, foi desenvolvido pelo filósofo alemão Karl Marx. Influenciado pela visão dialética de Hegel, pelo socialismo utópico de Saint-Simon, Fourier e Proudhon, pela leitura dos clássicos sobre economia de Adam Smith e David Ricardo e pelas ideias de Feuerbach, Marx edifica um sistema teórico que ao mesmo tempo em que se pretende uma filosofia da práxis, numa posição inovadora em relação a todas as filosofias anteriores, tenta, também, contemplar a visão objetivista e subjetivista dos positivistas e dos fenomenólogos.

Para o marxismo,

Os fenômenos sociais têm um caráter objetivo, mas, ao mesmo tempo, são sempre mediados pela consciência. $\mathrm{O}$ importante é não reduzir um aspecto ao outro, mas entender sua conexão. A pretensão de compreender os fenômenos apenas pelo significado que lhes conferem os sujeitos é ilusória; a tendência que oposta no sentido de eliminar o elemento subjetivo em favor da determinação de sua função é, por outro lado, reducionista. Os prejuízos de cada uma devem ser corrigidos de maneira imanente, fazendo-se interagir seus respectivos enfoques de maneira recíproca num contexto epistêmico mais avançado (RÜDIGER, 2002, p. 13).

O pensamento marxista concebe a busca pela verdade a partir da totalidade. A partir da escolha do objeto de estudo, o materialismo levanta formulações 
teóricas do universal para o particular até que se entenda o todo e, ao mesmo tempo, suas partes constituintes.

A concepção materialista parte da visão de que o entendimento da realidade deve nascer da análise da vida social concreta do homem, fundada na relação entre o conhecimento da base (as relações materiais que os homens estabelecem e os modos de produção que geram os meios de vida) e a superestrutura (a cultura e o mundo das ideias). Por isso, Marx concebe o homem como trabalho que intervém na natureza e dela retira os meios para sua sobrevivência. Ao criar e recriar seus meios de vida, os homens recriam a si próprios. Marx crê, assim, que a base (as forças produtivas) é que determina a superestrutura (as forças culturais). O homem é criação dele próprio e não produto das ideias de seu mundo. Em outras palavras: 'não é a consciência que determina a vida, mas a vida que determina a consciência'.

A produção das ideias e representações da consciência aparece no início diretamente entrelaçada coma a atividade material e o comércio material dos homens, como a linguagem da vida real. As representações, os pensamentos, o comércio espiritual dos homens se apresentam ainda aqui como emanação direta do seu comportamento material. O mesmo ocorre com a produção espiritual tal como se manifesta na linguagem da política, das leis, da moral, da religião, da metafísica etc, de um povo. Os homens reais e atuantes são os produtores de suas representações, de suas idéias etc, tal como se acham condicionados por um determinado desenvolvimento das forças produtivas e pelo intercâmbio que a ele corresponde até chegar às suas formações mais amplas. A consciência só pode ser o ser consciente, e o ser dos homens é seu processo de vida real. E se em toda a ideologia os homens e suas relações aparecem invertidos como numa câmara escura, este fenômeno resulta do seu processo histórico de vida, com a inversão dos objetos ao projetar-se sobre a retina do seu processo de vida diretamente físico (MARX; ENGELS, 1970, p. 27).

Tanto o positivismo como o materialismo e a fenomenologia foram sistemas filosóficos desenvolvidos no século XIX, no auge do Iluminismo e das mudanças sociais provocadas pela Revolução Industrial, pela Revolução Burguesa e pela Revolução Francesa. Nesse cenário, marcado pela sedimentação de um modo de vida conformado pelo industrialismo (seus empregos, salários, rendas e 
individualismo), pela urbanização (seus processos de interação e convivência em aglomerados sociais), pela secularização (a perda do poder do mundo eclesiástico e aristocrático), pela democracia (que passou a se espalhar pelo Ocidente e pelo Oriente), pela expansão do mundo da educação, da política e da informação (saciando o desejo das massas empoderadas pela nova ordem econômica), surge a necessidade de entender as novas formações sociais e seus processos internos de desenraizamento do homem de um mundo até então fundado nas tradições e nas certezas morais e políticas da ordem feudal.

Os três grandes sistemas filosóficos inspiram, dessa maneira, o nascimento de variações sociológicas que entendam o admirável mundo novo da modernidade. O Positivismo acabou gerando o surgimento da Sociologia Funcionalista e Estruturalista; a Fenomenologia gestou a aparição da Sociologia Compreensiva; e o Materialismo Histórico, Crítico e Dialético inspirou o surgimento da Sociologia Crítica.

Figura 2: Relação entre Teorias Filosóficas e Teorias Sociológicas

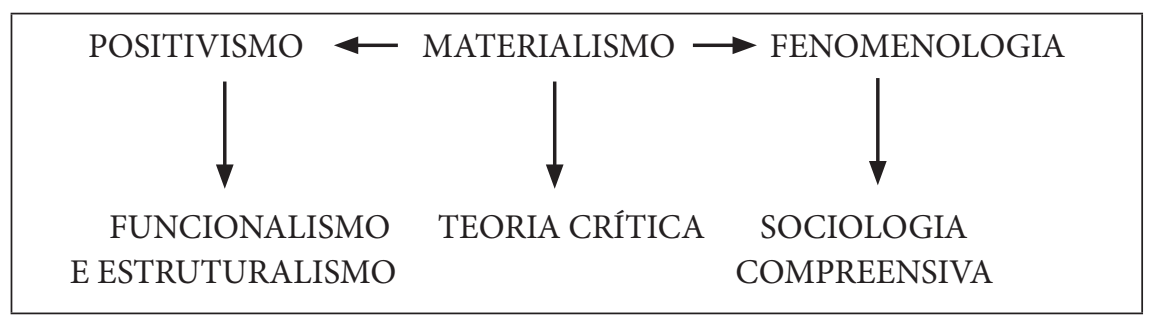

A Sociologia Funcionalista e Estruturalista surge no início do século XX, nos Estados Unidos, sobretudo com os trabalhos de Robert Merton e Talcott Parsons (1902-1979). Tributária da ideia do organicismo de Herbert Spencer e do evolucionismo de Charles Darwin, essa corrente teórica compreende que as sociedades humanas devem ser estudadas a partir dos mesmos princípios adotados nas ciências naturais. Dessa forma, o funcionalismo estabelece uma analogia entre a esfera biológica e a esfera humana. Ambas têm suas estruturas imanentes e preenchem funções (sociais ou biológicas) que, no fundo, visam apenas a manutenção da ordem de todo o sistema. Em outras palavras, tanto o mundo biológico como os seres humanos cumprem apenas funções dentro de um organismo (Spencer) que visa a evolução do sistema (Darwin). 
Nesse sentido, tanto o sujeito como o objeto têm o mesmo status teórico. O ser é visto como parte operacional da realidade, desempenhando um papel processual e meramente determinista. O objeto é tão somente uma estrutura que, apesar de sua complexidade, trabalha para a organização funcional do sistema.

Talcott Parsons concebe a Sociologia Estruturalista Funcionalista como uma ciência da ação, em que os atores são dotados de recursos materiais e simbólicos, usados para o cumprimento de suas tarefas. Parsons afirma que:

A ação social é o produto de opções individuais que têm sentido para o ator. Mas essas opções se acham ligadas a um conjunto global de valores comuns (expressão simbólica das preferências coletivas) e se inscrevem em uma rede de normas constitutiva da estrutura da sociedade, elementos coercitivos da ação individual (PARSONS apud LALLEMENT, 2004, p. 115).

De maneira geral, a tentativa de Parsons é estabelecer uma teoria analítica dos sistemas de ação social. Ele acredita que a estrutura da ação social dos indivíduos está cimentada num conjunto de relações e modalidades que configuram um regime de trocas estáveis entre os atores.

O ponto de partida fundamental é o conceito de sistemas sociais de ação [...] A interação de atores individuais ocorre sob tais condições que é possível tratar desse processo de interação como um sistema, no sentido científico, e submetê-lo à mesma ordem de análise teórica que, com êxito, é aplicada a outros tipos de sistemas em outras ciências (PARSONS, 1970, p. 3).

Seguidor de Parsons, Robert Merton refinou algumas reflexões funcionalistas, embora tenha introduzido o elemento crítico e autocrítico sobre a estrutura da própria disciplina. A Merton, incomodava que função fosse empregada como um conceito genérico demais para representar tantas concepções na Sociologia Funcionalista. Além disso, ao contrário da proposta universalizante de Parsons, Merton propõe que a investigação sociológica se dedique à missão de construir teorias de médio alcance, ou seja:

Teorias intermediárias entre as hipóteses menores que brotam cada dia em profusão no cotidiano trabalho da pesquisa, e as amplas especulações que partem de um grande esquema conceitual de onde se espera tirar um grande número de regularidades de comportamentos acessíveis ao observador (MERTON apud LALLEMENT, 2004, p. 131). 
Merton cria uma divisão, adotada posteriormente pelos funcionalistas, entre as funções manifestas e as funções latentes. As primeiras nascem dos atos conscientes dos indivíduos, dos grupos ou das sociedades e as demais têm caráter involuntário e inconsciente.

Para ilustrar o alcance desta dicotomia [funções manifestas e funções latentes], Merton desenvolve o exemplo do boss na máquina política americana. Ainda que sua forma de atuar seja muitas vezes condenada abertamente (racket político), o boss ocupa uma função chave necessária ao bom andamento da sociedade americana. Consiste em primeiro lugar em centralizar parcelas de poder esparramadas, a fim de responder necessidades que a administração está, muitas vezes, incapacitada legalmente para satisfazer. Assentada em um terreno local, a máquina política fornece, portanto, mais eficazmente, e de modo mais humano, auxílio e apoio às categorias desfavorecidas. Da mesma forma, com o auxílio de meios moralmente reprováveis [...], o boss distribui favores aos homens de negócios e lhes garante lucros rápidos e substanciais. [...] Como se pode constatar, são múltiplas as funções latentes. Do ponto de vista de Merton, basta para justificar, a despeito de muitas irregularidades que suscita, a conservação dessa instituição no seio da sociedade americana (LALLEMENT, 2004, p. 136).

A Sociologia Crítica está assentada nos pressupostos apresentados na filosofia da práxis de Karl Marx, mas ganha contornos singulares nas reflexões e nas obras de muitos de seus epígonos, como Theodor Adorno, Max Horkheimer, Louis Althusser, Herbert Marcuse, Karel Kosik, Henri Lefebvre, Georg Luckács (18851971), Antônio Gramsci (1891-1937), Karl Mannheim (1893-1947), Karl Korsch (1896-1961), Walter Benjamin, Norbert Elias, Siegfried Kracauer, Ernest Mandel, Ernest Bloch, Herbert Schiller, Michel Foucault, Cornelius Castoriadis, Fredric Jameson e Jurgen Habermas, entre tantos outros.

Partindo de uma visão dialética do movimento histórico e materialista que construiu e constituiu o homem, a Sociologia Crítica busca a conciliação entre a visão objetivista e subjetivista da sociedade e da realidade. Para ela, a sociedade é uma obra humana, criada pelas mãos e mentes do homem, num processo histórico contínuo e transformador do meio ambiente social, cultural e político. Isso não significa, entretanto, que o sujeito não seja, ao mesmo tempo, vítima de processos de coerção e de dominação que o subjugam às estruturas e às instituições e que 
o carreguem, contra sua autoconsciência, a condições materiais e espirituais que estão além de suas possibilidades de conhecimento e de reconhecimento.

Isso significa dizer que o sujeito é simultaneamente fruto de forças autônomas (internas) e heterônomas (externas), vivendo num constante processo dialético de soberania e subordinação, em que ora ele é o sujeito da ação ora ele é assujeitado pelas estruturas do mundo.

Tentando conciliar uma metodologia empírica e uma filosofia social, os sociólogos críticos entendem que a verdade social parte da necessidade da compreensão ontológica das essências e das aparências presentes na rede de acontecimentos sociais. Nem os fenômenos nem os fatos sociais revelam a verdade pura, se não houver o entendimento de que o fenômeno e o fato não contêm a essência da verdade, mas, que são apenas manifestação e representação, ou mera aparência. A busca, portanto, da Sociologia Crítica está em entender o fenômeno/fato como a coisa e a essência do fenômeno/fato como a coisa-em-si, a essência.

Dizendo isso, não queremos afirmar que a Sociologia Crítica nega os acontecimentos em detrimento das essências. No processo dialético, a realidade acontece nos fenômenos e nos fatos sociais, mas cabe ao sociólogo compreender que:

O conhecimento se realiza como separação de fenômeno e essência, do que é secundário e do que é essencial, já que só através dessa separação se pode mostrar a sua coerência interna e, com isso, o caráter específico da coisa. Neste processo, o secundário não é deixado de lado como irreal ou menos real, mas revela seu caráter fenomênico ou secundário mediante a demonstração de sua verdade na essência da coisa (KOSIK, 1976, p. 14).

O processo de desconstrução da verdade fetichizada da realidade, do mundo que se apresenta como real concreto e irrevogável, sustentado pelas cortinas das aparências, só pode ser efetivado pelo movimento dialético e histórico da Sociologia Crítica. Enquanto o homem não compreender os procedimentos internos de construção social da realidade por meio do pensamento dialético, a representação da coisa será para sempre tomada como a realidade natural e petrificada.

A distinção entre representação e conceito, entre mundo da aparência e o mundo da realidade, entre a práxis utilitária cotidiana dos homens e a práxis revolucionária da humanidade ou, numa palavra, a 'cisão do único', é o modo 
pelo qual o pensamento capta a 'coisa-em-si'. A dialética é o pensamento crítico que se propõe a compreender a 'coisaem-si' e sistematicamente se pergunta como é possível chegar à compreensão da realidade. [...] O pensamento que destrói a pseudoconcreticidade para atingir a concreticidade é ao mesmo tempo um processo no curso do qual sob o mundo aparência se desvenda o mundo real; por trás da aparência externa do fenômeno se desvenda a lei do fenômeno; por trás do movimento visível, o movimento real interno; por trás do fenômeno, a essência (KOSIK, 1976, p. 15-16).

Em linhas gerais, a base em que se estrutura essa corrente sociológica está, em síntese, na atitude crítica e dialética frente aos fenômenos humanos. Os sociólogos da corrente crítica buscaram examinar os efeitos do fetichismo da ideia da razão iluminista sobre a sociedade contemporânea e o campo prático da dominação política, das relações entre verdade e saber, além dos estragos provocados pelo industrialismo nos modos de produção e no consumo cultural em nosso tempo.

Nesse sentido, são emblemáticos os estudos de Adorno e Horkheimer sobre a falência do projeto iluminista, o nascimento de uma racionalidade instrumental e o processo de rendição da cultura à economia. Também são significativas as análises críticas empreendidas por Louis Althusser sobre a ideologia, de Antonio Gramsci sobre hegemonia e de Walter Benjamin sobre a deterioração da arte na era de sua reprodutibilidade técnica.

Quando se pergunta pelo objetivo da sociedade emancipada, obtêm-se respostas tais como a realização das possibilidades humanas ou a riqueza da vida. Tão ilegítima é essa questão inevitável, tão inevitável é o caráter repelente, impositivo, da resposta, que traz à lembrança o ideal social-democrata de personalidade, próprio daqueles naturalistas barbaças do século XIX, desejosos de gozar a vida. A única resposta delicada seria a mais grosseira: que ninguém mais passe fome (ADORNO, 1993, p. 137).

A Sociologia Compreensiva foi edificada pelo filósofo alemão Max Weber (1864-1920). Seu pensamento foge dos enquadramentos teóricos praticados em sua época, embora possa ser considerado como um renovador original do pensamento marxista. Weber refuta as filosofias teleológicas, escatológicas ou deterministas, toda forma de objetividade pura e a aridez conceitual dos metafísicos puros. Max Weber comunga da visão marxista da historicidade, da leitura econômica e da 
ação humana como empreendimento basilar da realidade, mas cria a sua própria visão para o entendimento da realidade social que cerca o sujeito e o objeto.

Weber considera a sociologia uma "ciência que pretende entender, interpretando-a, a ação social para, desta maneira, explicá-la causalmente em seu desenvolvimento e seus efeitos. Por ação, deve-se entender uma conduta humana (que pode consistir num ato externo ou interno; numa condição ou numa permissão) sempre que o sujeito, ou os sujeitos da ação, envolvam-na de um sentido subjetivo. A ação social, portanto, é uma ação em que o sentido indicado por seu sujeito ou sujeitos refere-se à conduta de outros, orientando-se por esta em seu desenvolvimento" (WEBER, 1969, p. 5).

Nessa chave de entendimento, Weber entende que o campo da epistemologia só pode ser o da ciência compreensiva e explicativa, nunca sumariamente descritiva ou meramente crítica. O papel da sociologia compreensiva é entender e explicar a ação dos homens e os valores que determinam seu comportamento. Em certa medida, Weber comunga com a visão de Dilthey, para quem os seres humanos são dotados de consciência, e agem de acordo com seus valores, racionalidades, crenças, representações etc.

O papel da sociologia compreensiva não é esquadrinhar estatística, laboratorial, empirica ou metafisicamente a ação social humana. Sua missão está em entender o sentido que os seres humanos atribuem às ações humanas. O centro desta pesquisa está na subjetividade, ponto de partida para a busca do verdadeiro processo de conhecimento.

Weber demonstrou em seus trabalhos que o próprio fazer científico não está assentado na objetividade pura, como pregam os positivistas tardios. Toda decisão científica é precedida por uma escolha, um juízo de valor, o que demonstra que todo percurso científico é delineado pela vontade humana e não pela ilusão de que existiria um roteiro frio e matemático nas ciências exatas. Para o pensador, a própria escolha do objeto a ser pesquisada, a opção pela busca desta ou daquela verdade, o caminho estabelecido entre sujeito e objeto, é dominado pelos valores humanos. Nesse sentido, não há ciência sem valores, nem relação de verdade entre sujeito e objeto, sem a dominância do sentido presente na mente do sujeito. 
Por sentido, entendemos o sentido subjetivo indicado pelos sujeitos da ação, seja: a) existente de fato: 1. num caso historicamente dado, 2. como média e como aproximação numa determinada massa de casos: ou b) construído num tipo ideal, com atores deste caráter (WEBER, 1969, p. 6).

Por tudo isso, Weber acredita que as ciências sociais só podem se determinar à compreensão dos acontecimentos sociais e culturais como singularidades, rejeitando toda forma de leis universais e determinismos. Em seus trabalhos, o filósofo alemão desenhou aquele que seria o método eficaz para a compreensão do sentido humano para as ações sociais, o tipo-ideal. Elaborando teoricamente alguns traços propositivos sobre uma determinada realidade, cabe ao 'tipo ideal' desenhar o que seria uma teoria simplificada do real, especificando seus traços, seus processos de causalidade e de explicação do fenômeno singular.

Os conceitos construtivos da sociologia são típico-ideais não só externa como também internamente. A ação real sucede, na maior parte dos casos, com obscura semiconsciência, ou com plena inconsciência de seu 'sentido indicado.' O agente 'sente' bem mais, de um modo indeterminado, do que 'sabe', ou tem idéia clara; atua, na maior parte dos casos por instinto ou costume. Só ocasionalmente - e numa massa de ações análogas, unicamente em alguns indivíduos - é que se eleva à consciência um sentido, seja racional ou irracional, da ação. Uma ação efetivamente com sentido, isto é, clara e com absoluta consciência é, na realidade, um caso limite. Toda consideração histórica ou sociológica tem que levar em conta esse fato em suas análises da realidade. Porém, isto não deve impedir que a sociologia construa seus conceitos, mediante uma classificação dos possíveis sentidos indicados, e como se a ação real transcorresse orientada conscientemente, segundo um sentido. Devemos sempre levar em conta e esforçamo-nos para precisar o modo e a medida da distância existente frente à realidade, quando se tratar do conhecimento desta em sua concretização. Muitas vezes nos encontramos, metodologicamente, perante a escolha entre termos obscuros e termos claros, mas estes irreais e típico-ideais. Neste caso, deve-se preferir cientificamente os últimos (WEBER, 1969, p. 18).

As três grandes matrizes filosófico/sociológicas acabaram sendo fonte e inspiração para os desdobramentos e as reflexões constituídas pelo campo das chamadas ciências da comunicação ao longo do século XX. A Sociologia Funcionalista acabou formatando diretamente a Teoria Funcionalista da Comunicação. A Socio- 
logia Crítica inspirou a Teoria Crítica, associada fortemente ao pensamento dos teóricos da Escola de Frankfurt. E a Sociologia Compreensiva fez surgir correntes de pensamento dentro da Escola de Chicago e da Escola de Grenoble.

Essas foram naturalmente as influências diretas sobre algumas das nossas principais teorias da comunicação. Entretanto, é evidente que a presença do funcionalismo, da teoria crítica e da sociologia compreensiva também se manifestem aqui e ali, em muitas das demais teorias da comunicação, seja em partes ou por influência ideológica. Cabe sempre ao pesquisador saber discernir as fontes de inspiração das teorias do conhecimento e o seu percurso filosófico e sociológico no arcabouço teórico das ciências da comunicação.

Figura 3: Relação entre Teorias Sociológicas e Teorias da Comunicação

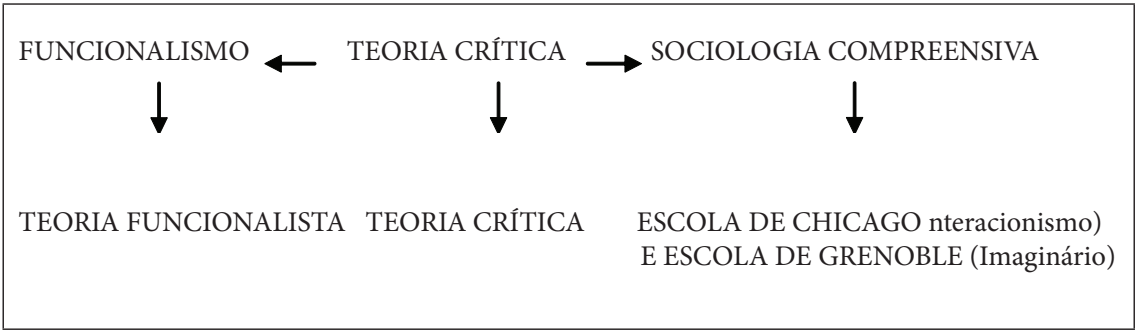

\section{The philosophical and sociological sources of theories of mass communication}

\section{Abstract}

This paper do the genealogy of theories of mass communication developed in the twentieth century. The intention is to seek and identify the origins of the major philosophical and sociological theories, linking thus the genetic history of the epistemological ideas that marked the communication thinking and determined the format, particularly in critical and functionalist theories. The work, developed through research and theoretical literature, seeks to establish a coherent history of the epistemology of theories of communication, in many contemporary works without proper original paradigmatic contextualization.

Keywords: Theories of communication. Theories of knowledge. Epistemology of communication. 
92 Univ. Arquitetura e Comunic. Social, Brasília, v. 6, n. 1/2, p. 71-92, jan./dez. 2009 Leandro Marshall

\section{Referências}

ADORNO, Theodor. Mínima moralia. São Paulo: Ática, 1993.

DARTIGUES, André. O que é fenomenologia. 2 ed. Rio de Janeiro: Eldorado, 1973.

DURKHEIM, Emile. Le suicide. Paris: Feliz Alcan, 1930.

HESSEN, Johannes. Teoria do conhecimento. São Paulo: M. Fontes, 2000.

KOSIK, Karel. Dialética do concreto. Rio de Janeiro: Paz e Terra, 1976.

KUHN, Thomas. A estrutura das revoluções científicas. São Paulo: Perspectiva, 2001.

LALLEMENT, Michel. História das ideias sociológicas: de Parsons aos contemporâneos. Petrópolis: Vozes, 2004.

MARX, Karl. O capital. Rio de Janeiro: Bertrand Brasil, 1991.

MARX, Karl; ENGELS, Friedrich. La ideologia alemana. Montevideo: Pueblos Unidos; Barcelona: Grijalbo, 1970.

PARSONS, Talcott. The social system. Londres: Routledge \& Kegan Paul, 1970.

RÜDIGER, Francisco. Ciência social crítica e pesquisa em comunicação. Porto Alegre: E@, 2002.

WEBER, Max. Economia y sociedad. México: Fondo de Cultura Econômica, 1969. 